\title{
Analysis of main points of channel freezing-thawing disease in cold region and influence of channel base soil on the disease
}

\author{
Liqing Liang * \\ Jilin agriculture science and technology university, Jilin, Jilin, China
}

\begin{abstract}
The frozen soil area in China is more than two thirds of the total territory, so the problem of frost heave is obvious. Especially in northeast, northwest, north China and other cold regions, the problem of frost heave of hydraulic structures is very common. Canal is a common hydraulic structure in agricultural water, which is affected by seasonal frozen soil and may cause problems such as lining damage, seepage and irrigation efficiency. Therefore, this paper mainly summarizes the necessity of research on channel freezingthawing damage, the research direction of channel freezing-thawing damage, and expounds the influence of seasonal frozen soil on freezing and thawing diseases in cold regions by taking the particle size of saturated soil based on channel as an example.
\end{abstract}

Keywords: Seasonal frozen ground; Channel; Freeze-thaw disease; Canal base

\section{Research necessity analysis}

Permafrost covers about one-fifth of the earth's surface area. China's permafrost area is 2.15 million square kilometers, ranking the third in the world, second only to the Soviet Union and Canada. If seasonal frozen ground is included, the frozen ground area in China is more than two-thirds of the total territory. Freezing damage to hydraulic structures is very common and serious in northeast, northwest and North China [1]. The winter climate in China's cold regions is cold and dry, and water delivery channels in irrigated areas are vulnerable to the damage of seasonal frozen soil freezing-thawing [2]. Small will cause leakage problems, affect the efficiency of irrigation, large will cause water interruption or even dike break and other accidents.

The investigation shows that the freezing damage of canal hydraulic structures in seasonal frozen regions is mainly caused by the influence of soil frost heaving and thawing on the structure and durability of materials. , this article analyzes the mechanism of these diseases, and cold and irrigation channels freeze-thaw including channel under the condition of freezing and thawing process, causes, occurrence regularity, disease characteristics, such as analysis, cold and freezing and thawing channel is determined based on the above disease types, for normal operation of the service life of cold and irrigation channels, which provides the theoretical foundation and maintenance management, etc.

\section{The main research direction is analysis}

Based on the 2015 project "Research on Soil Hydrothermal and Vertical Change of Frozen Layer in Winter -- Taking Jiuzhan Campus of Jilin University of Agricultural Science and Technology as an example", the research on frozen soil parameters in winter was carried out by investigating disease phenomenon and analyzing disease occurrence process. The following analysis directions were mainly sorted out through experiments and literature analysis.

\subsection{Analyze the characteristics of diseases in irrigation channels in cold area}

Relatively high latitude in the northeast in our country, the region in the channel project is located in the seasonal frozen, channel and linear engineering [3], along the channels affected by freeze-thaw action is bigger, frost heaving soil engineering area are widely distributed, and channel engineering winter without water requirement, water freeze damage did not occur because the channel, The diseases of all channels are mainly concentrated in lining diseases. Through field investigation and literature analysis, the causes and specific characteristics of soil freezing-thawing diseases of channels in northeast China are analysed[4], laying a foundation for the study of disease mechanism.

\footnotetext{
* Corresponding author: hhs_liangliqing@126.com
} 


\subsection{The mechanism of channel freezing-thawing disease was analyzed}

Channel soil frost heave soil is not only the central plains the freezing of water, but with winter canal in the inland waters not completely emptying and lead to freeze the underground water level is higher, the frozen soil depth within the scope of the capillary water, weak bonding water freezing continuously to cover the migration, frost heave effect is strong, and the frost heave deformation, destruction is more serious. Through field investigation, through the indoor experiment, such as the frost heave susceptibility analysis, systems apply soil permeability under impact experiment and so on, combined with literature analysis research channels disease occurs under the condition of cold and freezing and thawing process, the conditions, influencing factors, based on the division of channel under the condition of freezing and thawing of disease types, and preliminary study channels disease occurrence regularity of freeze-thaw conditions.

\subsection{The influence of channel concrete material on prevention of freezing injury was analyzed}

The frost resistance of channel lining concrete also has an influence on channel damage, mainly including the study of concrete material mix ratio and concrete performance. The combination of concrete materials, such as the amount of admixture, water-cement ratio, and the amount of new materials, such as differential foam, etc. [5]; On the basis of the above, the frost resistance and durability of concrete are studied, including the pore structure, freezing temperature, freezing rate, saturation, reliability analysis and carbonization of concrete[6-8].

Through the above three contents, how to control the disease in the design and construction process of the channel in cold areas, including new structure types, new impermeable materials, etc., to provide a basis for the service life, normal operation and maintenance management of the channel in cold areas irrigation area

\section{Effect of seasonal frozen soil as channel base on canal diseases}

According to the analysis of the causes and mechanism of the disease, the damage types of the freeze-thaw channel in the irrigation area in cold area can be divided into two types: frost heaving failure of the land at the bottom of the channel and freezing failure of water body in the channel. If the channel is not carried out in winter, the destruction of the channel due to the freezing and thawing action of soil base is the primary factor. If there is water in the channel in winter, the freezing damage caused by water freezing in the channel is the primary factor [9]. In northeast China, channel water is generally drained in winter due to channel maintenance and seasonal requirements, so the damage of channel caused by freezing and thawing of channel foundation soil becomes the main type.

Unsaturated soil, such as water seepage or groundwater recharge, replenish the gap between soil particles, so the frost heave is small, while saturated soil in negative temperature environment, soil particles pore water crystallization, when water recharge pore water, crystallization will continue to increase, causing soil expansion, thus affecting channel lining and causing frost heave failure. Therefore, the temperature field experiment of saturated soil was designed to analyze the temperature variation trend of each layer of saturated soil samples with different particle sizes in the freezing process under the same temperature condition. Taking this as an example, the influence of channel foundation soil on channel freezing-thawing disease was analyzed.

Seasonal frozen soil is unidirectional freezing at the top. In order to understand the internal temperature field of soil samples in the freezing process, unidirectional freezing at the top is adopted in order to simulate the conditions consistent with the real environment. First of all, the temperature in the box and the temperature at the top and bottom were set at $1^{\circ} \mathrm{C}$ for constant temperature. Then, according to the external environment of the frozen soil sample ice rate measurement test, the roof temperature was adjusted to $-20^{\circ} \mathrm{C}$ to monitor the internal temperature change of the sample.

\subsection{The experiment design}

Sample preparation: a layer of vaseline was coated on the plexiglass cylinder, and sand with particle size $\leqslant 0.25 \mathrm{~mm}$, $0.25-0.5 \mathrm{~mm}, 0.5-1 \mathrm{~mm}$ were layered into the plexiglass cylinder. In order to ensure the consistency with the samples measured by volume ice content of frozen soil samples, $353 \mathrm{~g}$ sand was packed into the cylinder each time, tamped to $3 \mathrm{~cm}$ high, and $1530 \mathrm{~g}$ sand was loaded into the cylinder four times to prepare dry soil samples with dry density of $1.5 \mathrm{~g} / \mathrm{cm} 3$. The filter was arranged at the bottom of the cylinder to ensure that no sand flowed out during the movement of the sand column. The prepared sand column was placed in a bucket, and the sample was saturated with water slowly added to the bottom. After water saturation, gravity water release was carried out to obtain saturated soil samples.

Sample installation: place the prepared soil sample on the bottom plate of the freeze-thaw test device, fix the fixing plate with screws, and wrap the insulation layer in the outer layer. To ensure the stable operation of the test box, connect the water refill device outside the box to the water refill channel at the bottom plate inside the box.

Temperature monitoring: In the whole freezing test process, the temperature of box body, roof and bottom plate is adjusted to $1^{\circ} \mathrm{C}$ for 6 hours, so that the temperature 
of each part of the sample is uniform, and then the roof temperature is adjusted to $-20^{\circ} \mathrm{C}$, until the soil reaches the frozen stable state. Temperature changes at $0 \mathrm{~cm}, 1.5 \mathrm{~cm}$, $3 \mathrm{~cm}, 4.5 \mathrm{~cm}, 6 \mathrm{~cm}, 7.5 \mathrm{~cm}, 9 \mathrm{~cm}$ and $10.5 \mathrm{~cm}$ were monitored at the bottom of the test.

\subsection{Test results and analysis}

A probe temperature sensor was inserted into the soil every $15 \mathrm{~mm}$, and the reading time interval was $10 \mathrm{~min}$ to monitor the internal temperature field of saturated sand samples with different particle sizes during freezing process. The dry density of soil samples used in the three tests was the same, and the temperature control of the top, bottom and three ends of the box body was the same. The freezing of soil samples with different particle sizes is shown in Fig 1-3. retention.

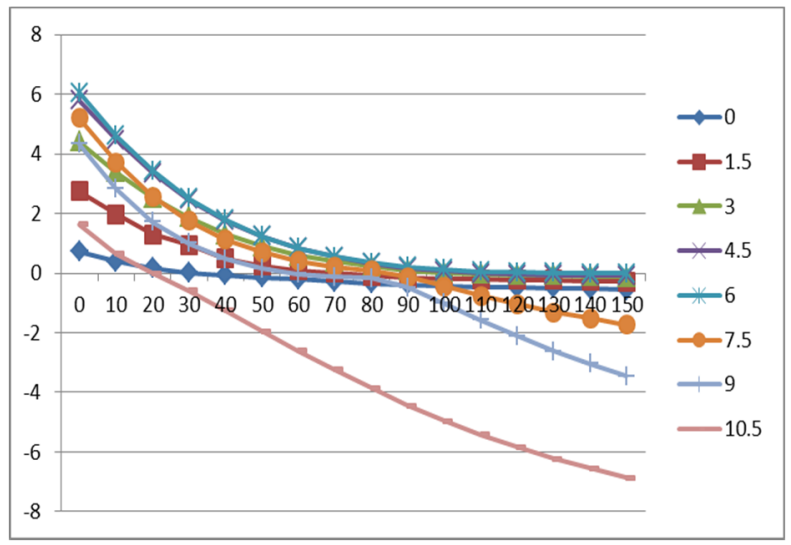

Fig.1 $\leqslant 0.25 \mathrm{~mm}$ sand column freezing temperature field

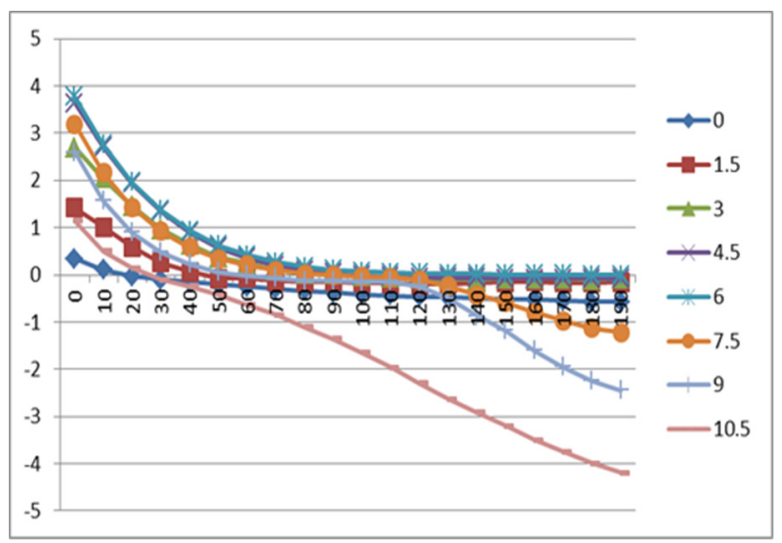

Fig.2 0.25-0.5 sand column freezing temperature field

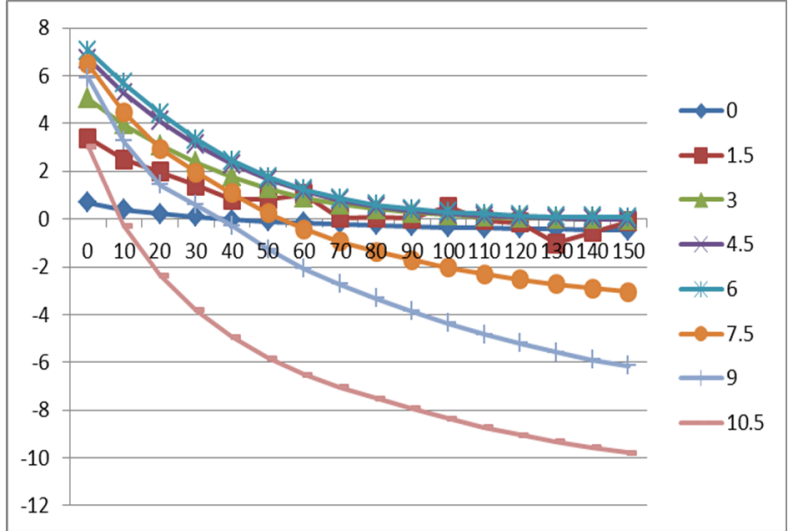

Fig.3 $0.5-1 \mathrm{~mm}$ sand column freezing temperature field

As can be seen from the figure, saturated soil samples with the same dry density and different particle sizes show basically the same temperature variation trend in each layer during the freezing process under the same temperature condition. The temperature of the soil samples at the top decreases rapidly under the influence of roof temperature, while the temperature of the soil in the middle decreases slowly, while the temperature of the soil at the bottom changes the most slowly with a very small amplitude. In the low-temperature environment of $20^{\circ} \mathrm{C}$ at the top, the freezing time of soil samples with different particle sizes is different. It takes $250 \mathrm{~min}$ to form stable low temperature inside the sand column with particle size of $0.5-1 \mathrm{~mm}, 190 \mathrm{~min}$ to reach negative temperature completely inside the sand column with particle size of $0.25-0.5 \mathrm{~mm}$, and only $140 \mathrm{~min}$ to reach negative temperature inside the sand column with particle size of $\leqslant 0.25 \mathrm{~mm}$. It can be seen from the experiment that the freezing time of saturated coarse sand sample is significantly longer than that of fine sand sample, which is because the coarse sand particle gap is large, water crystallization is slow and frost heaving time is long in the freezing-thawing process. It can be seen that the soil frost heave time is affected by the particle size of channel foundation soil.

\section{Summary}

To sum up, under the action of seasonal frozen soil, diseases caused by channel freezing and thawing damage mainly include channel lining and channel bottom foundation, etc. The research direction of channel diseases can be analyzed from the generation and classification of diseases, channel foundation soil freezing and thawing effect and influencing factors, and channel lining materials.

For seasonal frozen soil, the influence of freezing and thawing damage of channel foundation soil is mainly water condition and temperature. Through the temperature field experiment, it can be seen that the smaller the soil particles are, the more likely the saturated soil is to frost heave, and the greater the influence on channel is. 
As an important water conservancy project to improve irrigation water condition and adjust regional microclimate, the water conveyance channel plays an important economic, social and ecological benefits. The analysis of soil freezing-thawing mechanism is of great theoretical and practical significance to the study of soil moisture in irrigation and water conservancy and solute migration in agriculture and environment. It provides theoretical and technical basis for the construction plan, structure design, operation management and winter maintenance of the channel in the cold area irrigation area in the future, so as to improve the service life of the channel project in the cold area and reduce the cost.

\section{Acknowledgements}

Natural science research project of Jilin Institute of agricultural science and technology: " Mechanism analysis of freezing and thawing diseases in irrigation channels in cold regions " (no. : 20190625)

\section{References}

1. SUI Tieling. Simple Test of anti-freezing technology -- Lecture on anti-freezing technology knowledge of Canal System Hydraulic building [J]. Water Resources World,1988(06): 22-23.

2. Jia Zhiguo, Liu Guanglou, Han Yiting. Anti-frost heaving design of canal system in Inner Mongolia irrigation area downstream of Muzhuang Hydraulic Project [J]. Inner Mongolia Water Resources, 2019(03): 38-39.

3. HE SHANshan. Study on anti-frost heave design of lining channel in Liaoning Coastal irrigation area [D]. Shenyang Agricultural University,2017.

4. Li Haojun. Characteristics of freezing damage of canal seepage prevention project [J]. Private Science and Technology,2011(08):322.

5. Wang Yi, Liu Jincheng, Liu Quanhong, Wang Zhengzhong. Shape optimization of trapezoidal lining channel structure under temperature-watersoil-structure coupling effect in cold area [J]. Journal of tsinghua university (natural science edition) : 110

[2019-05-17].

https://doi.org/10.16511/j.cnki.qhdxxb.

2019.22.010.

6. Ma Jin-long, LI Zhao-yu, TIAN Wen, ZHANG Wanrui, LI Jia-min, SU An-shuang, CHANG Jun-de. Characteristics and causes of freezing damage of channel in cold area $[\mathrm{J}]$. Hydraulic science and cold area engineering,2018,1(11):28-33.

7. Zhang Xiaohui, Tong Yuxuan, Zhang Zhicheng. Characteristics and causes of freezing damage in lined channels and underground pipelines [J]. Forestry science and technology information,2011,43(03):73-74.

8. Nan Ruifang. Study on the law of frost resistance and durability deterioration of Hydraulic Concrete materials [D]. North China University of Water Resources and Electric Power,2015.

9. Xiu Lu. Analysis on frost heaving failure factors of channel slope protection in seasonal frozen region [D]. Heilongjiang University,2015. 